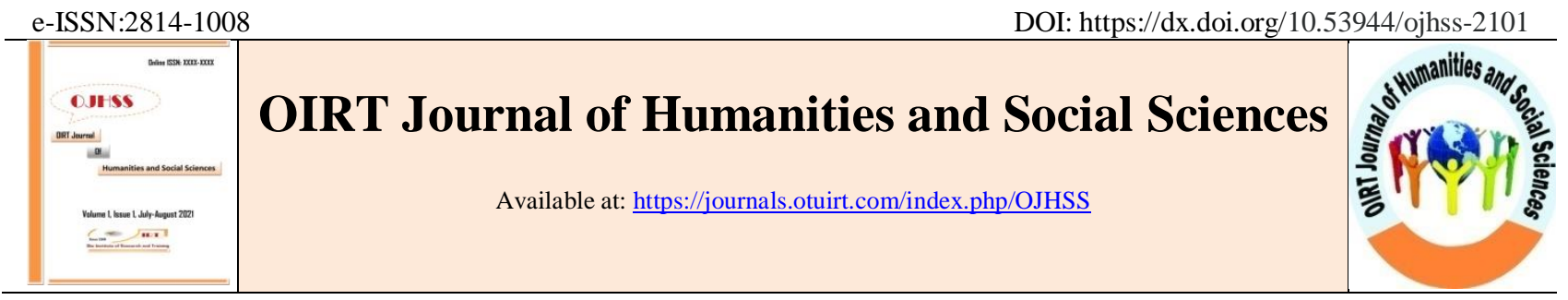

REVIEW ARTICLE

\title{
COVID-19 Pandemic: The Impact of Online-Schooling on Students' Engagement with School Work and Physical Activity
}

\author{
Chinyere Amaka Oruche* \\ Department of Development Studies, Faculty of Social Sciences, University of Dhaka, Bangladesh
}

Corresponding Author: Oruche Chinyere Amaka, Department of Development Studies, Faculty of Social Sciences, University of Dhaka, Bangladesh. Email: amakaogunleye@gmail.com

Copyright: ( ) the author (s), publisher, and licensee OIRT. It is an open-access article distributed under the terms of the Creative Commons Attribution Non-Commercial License, which permits unrestricted non-commercial use, distribution, and reproduction in any medium, provided there is a proper citation for the original work.

\begin{abstract}
The COVID-19 pandemic forced many sectors, including education, into an unprecedented global shutdown. COVID-19 school closures in Bangladesh started on March 17, 2020, and continued into 2021, affecting about 38 million students and close to one million teachers. Schools in Bangladesh were closed to both students and teachers. Educational activities were remotely directed via digital devices (online schooling). This article explores how homeschooling has affected students' active engagement with school work and physical activity in Grades 110 in Bangladesh. This study used a qualitative approach to clearly describe its aims and objectives; database sources, web search engines, direct observation, and relevant documents were used to obtain data for this study. It is recommended that the aspect of "teaching" be weakened and the element of "learning" be strengthened during this online-schooling phase to improve students' interest in learning and active engagement in schoolwork. There is also a clear positive relationship between the time students spend being physically active during a school day and their attention and effort toward schoolwork.
\end{abstract}

Keywords: COVID-19, Online Schooling, Pandemic, Physical Activity

Article History

\begin{tabular}{l|l} 
Received: August 06, 2021 & Revised: August 18, 2021
\end{tabular}

Accepted: August 22, 2021

\section{INTRODUCTION}

The novel coronavirus disease (COVID-19) continues to spread and cause shockwaves across the globe. The World Health Organization (WHO) declared the virus an International Public Health Emergency on January 31, 2020, and said it was a pandemic on March 11, 2020. COVID-19 has caused an overwhelming public health crisis, affecting many sectors, including education, and has also affected the usual functioning of schools. Social distancing has meant that schools in various countries had to close their doors and switch to remote learning using live or recorded broadcasts, online teaching/group communication using multiple apps, and softwarebased homework submission. The online learning tools became important for short to medium-term solutions to the COVID-19 pandemic. One year into 
the COVID-19 pandemic, over 200 million students, which is $11.5 \%$ (UNESCO, 2021) across 24 countries, are still affected by partial or complete school closures as of May 16, 2021. Over 100 million additional children will fall below the minimum proficiency level in reading due to the health crisis (UNESCO, 2020a). Because of the shutdown of schools and colleges in 2020, 1.5 billion children and youth across the 188 countries were affected by the teaching-learning process, which was $72 \%$ of the world's student population by May 11, 2020 (UNESCO, 2020b). Students are engaged when drawn in their work, persist despite its challenges and obstacles, and take visible delight in accomplishing their work. Student participation in school work is also seen as an outcome of school improvement. Millions of students have experienced the disruption of physical education and activity due to the closures of schools caused by the COVID-19 pandemic. This paper attempts to review the impact of Onlineschooling on students' engagement with school work and physical activity during the pandemic to devise strategies to adapt to such situations now and in the future. It is essential as the World Health Organization (WHO, 2020) has predicted more global pandemics in the future.

\section{MATERIALS AND METHODS}

This review was searched from January to May 2021 to track new developments and published reports and articles. This study used a qualitative approach to describe its aims and objectives clearly. The study focused on both primary and secondary data. World Health Organization (WHO), Organisation for Economic Co-operation and Development (OECD), United Nations International Children's Emergency Fund (UNICEF), and other scientific databases and web engine searches contributed the primary data for this study. Direct observation and relevant documents/reports, such as those from the Institute of Epidemiology, Disease Control and Research (IEDCR), the Directorate General of Health Services (DGHS), and the Bangladesh Ministry of Education, were used to compile secondary data. The information on COVID-19 and its impact on online schooling, student participation in schoolwork, and physical activity served as the inclusion criterion. Therefore, reports not wholly focused on the topic of this study were excluded. However, all of the papers were examined, emphasizing the impact of the COVID-19 pandemic in Bangladeshi schools.

\section{RESULTS AND DISCUSSION}

A survey on the education conditions in some countries and the methods used to improve educational opportunities during the pandemic found that the online learning that took place during the period when schools were closed was, at best, a small fraction of what students would have learned in school (Reimers \& Schleicher, 2020). This survey has made evident the benefits students gain from learning in close contact with their teachers and peers rather than online. The many benefits include free and complete access to various services offered in school, such as educational, social, and healthrelated. Reopening schools has undeniable advantages in promoting and supporting students' growth and development of knowledge and skills and growing their long-term economic contribution. In addition, the learning loss that has occurred during online schooling, if not addressed, will likely have a financial impact on societies in the form of lower productivity and development. Families will also benefit economically from reopening schools because it allows them to return to work once public health officials determine that it is safe. These benefits, however, must be carefully weighed against the health risks and sanitary measures needed to minimize the health impact of the pandemic. Previous epidemics suggest that school closures can prevent up to $15 \%$ of infections (OECD, 2020). Although this impact is small compared to other public health policy interventions such as workplace social distancing can reduce transmission by up to 73 percent, case isolation at about 45 percent, and household quarantine by around 40 percent (OECD, 2020).

In a study to analyze students' preparedness, participation, and classroom activities regarding online classes during the covid-19 pandemic in Bangladesh, the research findings revealed a lack of readiness, participation, and less scope of classroom activities through online learning. Problems of infeasible internet consistency and electricity, paying attention, and understanding lessons through the online platform are the main constraints of online learning in a developing country like Bangladesh (AlAmin et al., 2020). In a similar study to investigate 
the current status of online education and Covid-19 impacts on the educational system in Bangladesh, teachers were discovered to be undertrained and lacking sufficient knowledge of technology to conduct online classes. On the other hand, many students cannot participate in online courses due to their low socioeconomic level, lack of access to digital devices, and poor internet connection, especially those living in remote areas. Students also lack concentration during online classes because of the new class format and poor lecture presentation of teachers (Mahmud et al., 2021). Compared to children from socioeconomically disadvantaged families, well-off families are more likely to access resources for learning continuity and educated and involved parents. Therefore, they are less likely to be impacted by income loss, according to a World Bank study published in 2020. (World Bank, 2020).

According to a survey conducted in China, most students, parents, and teachers thought homeschooling/online learning was acceptable at first. Positive attitudes are perceived to impact academic achievement in students positively. However, about a quarter of teachers were concerned that this learning style would reduce their students' interest in learning (Nunez \& Leon, 2016). A student's enthusiasm for education and involvement in schoolwork is one of the essential elements impacting their academic achievement. The aspect of "teaching" is weakened, and the element of "learning" be strengthened during online schooling to maintain and improve students' interest in learning and engagement in schoolwork (Renninger, 2016). Students can by themselves discover and summarize information through explorative reading and research assignments. Interaction is a good indicator of whether or not a student is paying attention in class. In-class interaction and engagement with classwork will improve students' understanding and promote the learning effect (Chen, 2020). During online courses, teachers pay more attention to a small portion of students that interact and participate. They may neglect the ones that are not proactive, hence adversely affecting academic performance. Setting up a study room at home similar to the classroom, making the students dress in school uniforms before classes, and entering the study room as if entering the classroom are all ways to improve online learning. Teachers can replace live/recorded broadcasts with online conferences/virtual classrooms to effectively see and monitor students as they do in the school (Eraikhuemen, 2015).

Physical education (PE) that would typically occur in school has been canceled entirely or made a part of digital homeschooling. The research documented that physical activity plays a vital role in children and young people's physical and psychosocial health and well-being (Biddle et al., 2019). There is sufficient evidence that a sedentary lifestyle in students is associated with chronic diseases later in life and other health-related risk behaviors such as unhealthy dietary patterns (Carsonet et al., 2016). Another key finding of physical activity during online school is that the most active students also worked well with remote schooling. There was a clear positive relationship between the time students spent being physically active during a school day and their engagement and effort toward schoolwork. In times of online schooling, policymakers and educators need to discuss whether the degree of physical activity should be a result of parents' initiative or if the schools to a more significant degree, could provide students with tasks and assignments requiring them to systematically engage in physical activity at home (Roe et al., 2021).

\section{CONCLUSION AND RECOMMENDATION}

This study aims to understand how active students engage in schoolwork during online homeschooling and how physically active they are. The pandemic has significantly disrupted academic activities, and online schooling has become a lifeline and best alternative for students/teachers during this period. However, during the period schools were closed, online education is, at best, only a tiny proportion of what students would have learned in school. The limitation is due to access and affordability of the internet, knowledge of digital devices for educational purposes, availability of resources, and a pleasing environment conducive to learning. Students benefit more from learning in close contact with their teachers and peers rather than online. The many benefits include free and complete access to various services offered in school, such as educational, social, and health-related. Students from disadvantaged backgrounds are often left out or behind when schools remain shut down. Administrators and policymakers should strengthen 
online schooling by providing alternatives to technological constraints. A significant factor affecting students' academic success is their interest in learning and involvement in schoolwork; the teachers should ensure the aspect of education is strengthened more than teaching by adjusting the teaching process to be more interactive. So that they can effectively monitor the students as they do in the classroom. In terms of physical activities during homeschooling, policymakers and educators should decide if physical activities should be parents' responsibility or schools could, to a greater extent, provide students with tasks and assignments requiring them to engage in physical activity at home regularly.

\section{Acknowledgment}

The author wishes to express sincere thanks to the researchers and Journals that published these valuable articles on the impact of online schooling on student engagement in work and physical activity during the COVID-19 pandemic.

\section{Conflict of Interest: None}

\section{Funding/Support: None}

\section{REFERENCES}

Al-Amin, M., Al Zubayer, A., Deb, B., \& Hasan, M. (2021). Status of a tertiary level online class in Bangladesh: students' response on preparedness, participation, and classroom activities. Heliyon, 7(1), e05943.

Biddle, S. J., Ciaccioni, S., Thomas, G., \& Vergeer, I. (2019). Physical activity and mental health in children and adolescents: An updated review of reviews and an analysis of causality. Psychology of Sport and Exercise, 42, 146-155.

Carson, V., Hunter, S., Kuzik, N., Gray, C. E., Poitras, V. J., Chaput, J. P., ... \& Tremblay, M. S. (2016). Systematic review of sedentary behavior and health indicators in school-aged children and youth: an update. Applied physiology, nutrition, and metabolism,41(6), S240S265

Chen, W. (2020). Disagreement in peer interaction: Its effect on learner task performance. System, 88, 102179.
Eraikhuemen, L. (2015): Quality Assurance in Mathematics Teacher Education Via Open And Distance Learning.

Mahmud, A., Dasgupta, A., Das Gupta, A., Hasan, M. D., \& Kabir, K. R. (2021). Current Status about Covid-19 Impacts on Online Education System: A Review in Bangladesh. Kazi Rafia, Current Status about COVID19 Impacts on Online Education System: A Review in Bangladesh (February 15, 2021).

Núñez, J. L., \& León, J. (2016). The Mediating Effect of Intrinsic Motivation to Learn on the Relationship between Student's Autonomy Support and Vitality and Deep Learning. The Spanish Journal of Psychology, 19.

OECD (2020). Flattening the COVID-19 peak: Containment and mitigation policies. https://read.oecdilibrary.org/view/?ref=124_124999\%2 0yt5ggxirhc\&title=Flattening_the_COVID-19_peakContainment and mitigation policies [Accessed on July 25, 2021]

Renninger, K. A., \& Hidi, S. E. (2015). The power of interest for motivation and engagement. Routledge.

Roe, A., Blikstad-Balas, M., \& Dalland, C. P. (2021). The impact of COVID-19 and homeschooling on Students' engagement with physical activity. Frontiers in sports and active living, 205.

Reimers, F., \& Schleicher, A. (2020). Schooling disrupted, schooling rethought. How the COVID-19 Pandemic is Changing Education. Retrieved December 14, 2020.

UNESCO (2020a). UNESCO Report-COVID-19, Education from Disruption to Recovery, available at: https://en.unesco.org/covid19/educationresponse/ [Accessed on July 08, 2021].

UNESCO (2020b). "Global monitoring of school closures caused by COVID-19", available at: https://en.unesco.org/covid19/educationresponse [Accessed on July 08, 2021].

UNESCO (2021). COVID-19 Education: from disruption to recovery: https://en.unesco.org/covid19/educationresponse/ [Accessed on July 08, 2021].

WHO (2020). "Coronavirus disease (COVID-19) situation report", Available at https://www.who.int/docs/defaultsource/coronaviruse/situation/reports [Accessed on July 08, 2021].

World Bank (2021). Keeping Bangladesh's Students Learning during the COVID-19 pandemic, https://www.worldbank.org/en/results/2021/04/18/keepi ng-bangladesh-s-students-learning-during-the-covid-19pandemic [Accessed on July 08, 2021].

World Bank (2020). The COVID-19 Pandemic: Shocks to Education and Policy Responses. World Bank, Washington, DC. 